\title{
Spectrochemical Investigations of Preferential Solvation. Fluorescence Emission Behavior of Select Polycyclic Aromatic Hydrocarbon Solute Probes Dissolved in Mixed Solvents
}

\author{
William E. Acree, Jr.," Sheryl A. Tucker, and Denise C. Wilkins \\ Department of Chemistry, University of North Texas, Denton, Texas 76203-5068
}

Received: March 24, $1993^{\circ}$

\begin{abstract}
A spectrofluorometric method is developed to examine preferential solvation of a probe molecule dissolved in binary solvent mixtures. The method assumes that the solvational sphere around every fluorophore is solvated by only one type of solvent component and that each solvated fluorophore contributes to the measured emission intensity. Expressions derived from the model are illustrated using observed fluorescence emission behavior of pyrene, benzo[e]pyrene, benzo[ghi]perylene, and coronene dissolved in binary $n$-heptane $+1,4$-dioxane, $n$-heptane + tetrahydrofuran, methanol + acetonitrile, and dibutyl ether + acetonitrile solvent mixtures, which were measured as part of the present study. Also discussed are deficiencies inherent in several of the spectrofluorometric probe methods published in the chemical literature.
\end{abstract}

\section{Introduction}

Spectroscopic probe techniques provide a convenient experimental means to study preferential solvation, which can be used to support (or perhaps to discredit) interpretations derived from calorimetric and other thermodynamic data. The method involves the use of a probe molecule (such as Reichardt and Dimroth's pyridinium $N$-phenoxide betaine dye, ${ }^{1,2} N$-alkylpyridinium iodides, ${ }^{3-5}$ pyrene, ${ }^{6,7}$ etc.) that exhibits different spectroscopic characteristics depending upon the properties of the solubilizing media. The probe molecule selectively binds to a specific surface site, partitions into an organized structure, or is preferentially solvated by one of the solvent components. Appearance of new spectral bands, shifts in the absorption and/or fluorescence emission wavelengths, or changes in the emission intensities provide an indication of the microenvironment immediately surrounding the probe.

Preferential solvation arises whenever the proportion of molecules of any given solvent component within the probe's solvational microsphere is not equal to its bulk mole fraction composition as is depicted in Figure 1. "True preferential solvation" is extremely difficult, if not impossible, to model rigorously because there is no guarantee that probe-solvent $A$ and probe-solvent $B$ molecular interactions remain independent of other solvent molecules within the solvational sphere. Solventsolvent interactions may lead to synergistic effects. Although not always stated explicitly, most published spectroscopic probe techniques $4,5,8-12$ assume a more idealized situation where solventsolvent interactions are neglected and the measured spectral response, $R$, in a binary solvent mixture is given by

$$
R=Y_{\mathrm{A}} R_{\mathrm{A}}^{\circ}+\left(1-Y_{\mathrm{A}}\right) R_{\mathrm{B}}^{\circ}
$$

a weighted local mole fraction or volume fraction average of the probe's spectral responses in the two pure solvents, $R_{\mathrm{A}}{ }^{\circ}$ and $R_{\mathrm{B}}{ }^{\circ}$. Here $Y_{\mathrm{A}}$ and $1-Y_{\mathrm{A}}$ refer to the solvational sphere composition, which may be quite different from the overall bulk liquid-phase composition, $X_{\mathrm{A}}$ and $1-X_{\mathrm{A}}$. Rigorous derivation of eq 1 from fundamental spectroscopic principles requires that one assume that the solvational sphere around every solute probe is solvated by only one type of solvent molecule. A second possibility that assumes that the solute's molar absorptivity coefficient and/or fluorescent quantum yield are simple compositional averages of pure solvent values is not applicable, since this already presupposes the final derived equation. A third trivial derivation would

- To whom correspondence should be addressed.

- Abstract published in Advance ACS Abstracts, October 1, 1993.

\section{TRUE PREFERENTIAL SOLVATION}

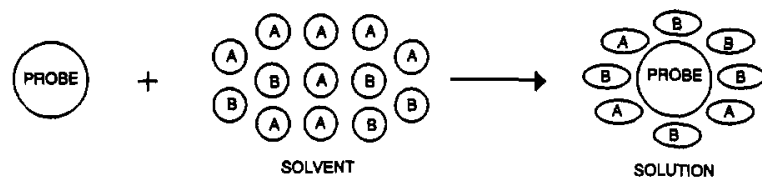

SIMULATED PREFERENTIAL SOLVATION

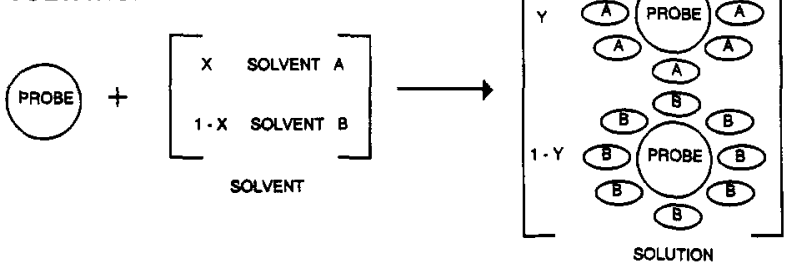

Figure 1. Schematic representation depicting important differences between true preferential solvation and models commonly used to simulate preferential solvation in binary solvent mixtures. In the simulated case, the solvational sphere around every probe molecule is assumed to be solvated by only one type of solvent component. Extent of preferential solvation is thus determined by the relative mole numbers of each solvational sphere type, rather than by the local mole fraction composition within the solvation sphere as is the actual case.

necessitate an identical spectral response in each pure solvent (i.e., $R_{\mathrm{A}}^{\circ}=R_{\mathrm{B}}^{\circ}$ ), in which case the solute would not exhibit probe character. The mathematical derivation of eq 1 , as it pertains to polycyclic aromatic hydrocarbon solvent polarity probes, will be discussed in greater detail in the Results and Discussion section. More sophisticated approaches ${ }^{13}$ also incorporate molecular size disparity and permit the solute to have a different coordination number in the binary solvent than in the pure solvents.

During the past seven years, our spectroscopic probe studies have focused primarily on identifying suitable polycyclic aromatic hydrocarbon (PAH) and polycyclic aromatic nitrogen (PANH) molecules for subsequent preferential solvation studies involving various HPLC stationary phases in contact with a binary mobile phase solvent mixture. Previous measurements ${ }^{14-28}$ revealed that pyrene, benzo[ghi]perylene, coronene, ovalene, benzo[ $e]$ pyrene, benzo $[a]$ coronene, naphtho $[8,1,2 a b c]$ coronene, dinaphtho $[8,1,2-$ $\left.a b c: 2^{\prime}, 1^{\prime}, 8^{\prime} \mathrm{klm}\right]$ coronene, dibenzo[def,p] chrysene, phenanthro$[5,4,3,2$ efghi]perylene, benzo[rst $]$ pentaphene, 1-azabenz $[a]-$ anthracene, 2-azabenz [a] anthracene, 12-azabenzo[a]pyrene, phenanthro $[2,3 h]$ isoquinoline, and phenanthro $[3,2 h]$ isoquinoline exhibit probe character as evidenced by systematic variation of 
emission intensity ratios with solvent polarity. Interestingly, only 25 of the 100 compounds studied to date behave in this fashion. Various emission intensity ratios of perylene, dibenzo[bc,ef]coronene, benzo $[a]$ pyrene, benzo[pqr]naphtho $[8,1,2 b c d]$ perylene, dibenzo $[f g, i j]$ pentaphene, 1-azapyrene, 2-azapyrene, 4-azapyrene, and several other PAHs/PANHs remained essentially constant, irrespective of solvent polarity.

Now that our supply of PAH/PANH benzenoids, fluorenoids, fluoranthenoids, and acenaphthylene derivatives has been exhausted, we have redirected our experimental efforts to a systematic examination of preferential solvation. In this paper, we report the fluorescence behavior of pyrene (Py), benzo[ghi]perylene (BPe), benzo[e]pyrene (BePy), and coronene (Cor) dissolved in binary $n$-heptane $+1,4$-dioxane, acetonitrile + dibutyl ether, methanol + acetonitrile, and $n$-heptane + tetrahydrofuran solvent mixtures. Results of these measurements, in conjunction with a newly derived equation for preferential solvation based upon additivity of fluorescence emission spectra, are used to deduce the composition of the solvational sphere surrounding the four PAH probe molecules. For informational purposes, we note that several published papers ${ }^{29-32}$ have appeared in the chemical literature reporting the fluorescence behavior of pyrene dissolved in or in contact with binary solvent systems. Our paper differs significantly from these earlier studies in that we are critically examining spectroscopic probe techniques and developing a methodology to exmaine preferential solvation on the basis of the photochemical properties of PAH solvent polarity probes. In the earlier works, the authors were either searching for possible correlations between the Py solvent polarity scale versus solubility data or versus chromatographic retention times, or establishing calibration curves in hopes of determining the liquid-phase composition which was adsorbed onto various chromatographic stationary phases.

\section{Materials and Methods}

Coronene, benzo[ $e]$ pyrene, pyrene, and benzo[ghi]perylene were purchased commercially from Aldrich Chemical Company in the highest purity available. The latter two solutes were recrystallized several times from absolute ethanol before use. Stock solutions were prepared by dissolving solutes in dichloromethane. Known aliquots of the stock solutions were transferred into test tubes, allowed to evaporate, and diluted quantitatively with the solvent of interest. Final solute concentrations of $10^{-5}$ $\mathbf{M}$ (or less) were sufficiently dilute to minimize inner-filtering artifacts. Solvents were of HPLC, spectroquality, or AR grade, purchased commercially from Aldrich Chemical Company, and the resulting solutions were optically dilute (absorbance $\mathrm{cm}^{-1}<$ 0.01 ) at all wavelengths so as to minimize undesired primary and secondary inner-filtering artifacts. ${ }^{33}$ Binary solvent mixtures were prepared volumetrically with burets so that stoichiometric mole and volume fraction compositions could be calculated to \pm 0.01 or better.

Absorption spectra were recorded on a Bausch and Lomb Spectronic 2000 and a Hewlett-Packard 8450 A photodiode array spectrophotometer in the usual manner. The fluorescence spectra were run on a Shimadzu RF-5000U spectrofluorometer with the detector set at high sensitivity. Solutions were excited at $338 \mathrm{~nm}$ (Py), $380 \mathrm{~nm}(\mathrm{BPe}), 334 \mathrm{~nm}$ (Cor), and $335 \mathrm{~nm}$ (BePy). Fluorescence data were accumulated in a quartz $1-\mathrm{cm}^{2}$ cuvette at $19^{\circ} \mathrm{C}$, ambient temperature, with excitation and emission slit width settings of 15 and $3 \mathrm{~nm}$, respectively. Emission spectra obtained represent a single scan which was then solvent blank corrected and verified by repetitive measurements.

\section{Results and Discussion}

The various PAH polarity scales, defined as ratios of emission intensities of select vibronic bands, ${ }^{6,14-28}$ provide a quantitative measure of solvent polarity and structure. Figure 2 depicts the

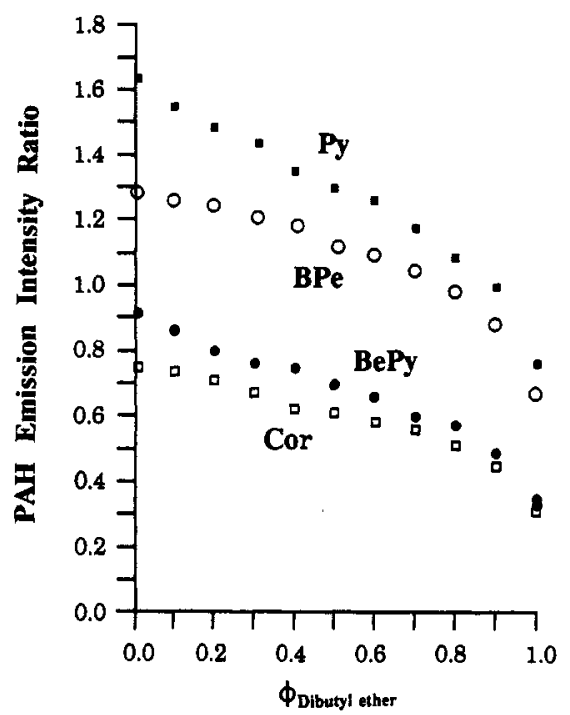

Figure 2. Variation of fluorescence emission intensity ratios with stoichiometric volume fraction composition for pyrene $(\mathrm{Py}, \boldsymbol{a})$, benzo[e]pyrene (BePy, $)$, benzo[ghi] perylene $(\mathrm{BPe}, \mathrm{O})$, and coronene (Cor, a) dissolved in binary dibutyl ether + acetonitrile solvent mixtures. Specific emission intensity ratios used were Py = I (circa $371 \mathrm{~nm}$ )/III (circa 382 $\mathrm{nm}) ;$ Cor = I (circa $426 \mathrm{~nm}) / \mathrm{III}($ circa $444 \mathrm{~nm}) ; \mathrm{BPe}=\mathrm{I}$ (circa 405 $\mathrm{nm}) / \mathrm{III}$ (circa $417 \mathrm{~nm})$; and BePy = I (circa 376)/II (circa $386 \mathrm{~nm})$. Emission band wavelengths are solvent dependent and may differ slightly from one spectrofluorometer to another because of errors or uncertainties in the emission monochromator calibration.

variation of intensity ratios of $\mathrm{Py}, \mathrm{BPe}, \mathrm{Cor}$, and $\mathrm{BePy}$ with stoichiometric volume fraction composition for the binary dibutyl ether + acetonitrile solvent system. Reproducibility of each measured numerical value is estimated to be \pm 0.02 on the basis of replicate measurements for select binary mixtures, which were independently prepared. Examination of Figure 2 reveals that the experimental intensity ratios are not a simple stoichiometric volume fraction average of the pure solvent values. Most values lie above the line connecting the two end values and suggest that the probes "see" a more polar microenvironment than would be expected from stoichiometric composition.

From a theoretical standpoint, variation of emission intensity ratios with solvent composition can be mathematically modeled in a relatively straightforward manner. The solvational sphere around every PAH fluorophore is assumed to be solvated by only one type of solvent molecule, either by solvent $A$ or by solvent B, as depicted in the simulated preferential solvation scheme of Figure 1. Extent of preferential solvation is thus determined by the relative mole numbers of each solvational sphere type, rather than by the local mole fraction composition within the solvation sphere. Each solvated fluorophore contributes to the observed fluorescence signal, $F_{\text {obe, }}$ at each emission wavelength scanned

$$
F_{\text {obs }}=K_{\text {fluoro A }}^{\prime}\left(P_{0}-P_{\text {fluoro A }}\right)+K_{\text {fluoro } \mathrm{B}}^{\prime}\left(P_{0}-P_{\text {fluoro B }}\right)
$$

where $P_{0}$ refers to the intensity of the incoming monochromatic excitation radiation and $\left(\mathrm{P}_{0}-P_{\text {fluoro }}\right)$ is the amount of radiation absorbed by solvated fluorophore type $i$. The two proportionality constants, $\boldsymbol{K}_{\text {fluoro } \mathrm{A}}^{\prime}$ and $\boldsymbol{K}_{\text {'fluoro B, depend upon the various optical }}^{\prime}$ component placements within the instrument, detector response/ efficiency, and quantum yield of the given solvated fluorophore. As noted in the Introduction, this particular solvational scheme is identical in concept to that used in a number of published spectroscopic probe studies; $4,5,8-12$ however, other researchers have not always explicitly stated the underlying assumptions necessary to derive eq 1 . Had one elected not to invoke this simplified solvational model, then $\boldsymbol{K}_{\text {fnuoro }}$ and/or ffluoro (discussed below) could be solvent dependent, and one would have to assume some mathematical function for how both parameters vary with binary solvent composition. 
The Beer-Lambert law relates the intensity of unabsorbed excitation radiation, $P_{\text {fluoro }}$, to the molar concentration of the fluorophore, [fluoro $i$ ], and the molar extinction coefficient, $\epsilon_{\text {fluoro }} i$.

$$
P_{\text {fluoro } i}=P_{0} 10^{-b \text { fnuoro }_{\text {ilfuoro } i} \text { ] }}
$$

Substitution of eq 3 into eq 2 gives

$$
\begin{gathered}
F_{\text {obs }}=K_{\text {fluoro A }}^{\prime} P_{0}\left(1-10^{-b \epsilon_{\text {nuoro A }}[\text { fluoro A }]}\right)+ \\
K_{\text {fluoro B }}^{\prime} P_{0}\left(1-10^{-b \epsilon_{\text {fuoro B }}[\text { fluoro B] }}\right)
\end{gathered}
$$

which can be expanded as a Maclaurin power series to yield

$$
\begin{aligned}
& F_{\text {obs }}= \\
& K_{\text {fluoro A }}^{\prime} P_{0}\left\{2.303 b \epsilon_{\text {fluoro A }}[\text { fluoro A }]-\left(2.303 b \epsilon_{\text {fluoro A }} \times\right.\right. \\
& \left.[\text { fluoro A }])^{2} / 2 !+\left(2.303 b \epsilon_{\text {fluoro A }}[\text { fluoro A }]\right)^{3} / 3 !-\ldots\right\}+ \\
& K_{\text {fluoro } \mathrm{B}}^{\prime} P_{0}\left\{2.303 b \epsilon_{\text {fluoro } \mathrm{B}}[\text { fluoro B }]-\left(2.303 b \epsilon_{\text {fluoro B }} \times\right.\right. \\
& \left.[\text { fluoro B }])^{2} / 2 !+\left(2.303 b \epsilon_{\text {fluoro } \mathrm{B}}[\text { fluoro B }]\right)^{3} / 3 !-\ldots\right\}
\end{aligned}
$$

For very dilute solutions where $2.303 b \epsilon_{\text {fluoro i }}$ [fluoro $i$ ] $<0.05$, the higher order terms are negligible. Performing this simplification, the measured emission is

$$
\begin{aligned}
& F_{\text {obs }}=2.303 K_{\text {fluoro } \mathrm{A}}^{\prime} P_{0} b \epsilon_{\text {fluoro } \mathrm{A}} Y_{\mathrm{A}} \text { [fluoro] }+ \\
& 2.303 K_{\text {fluoro } \mathrm{B}}^{\prime} P_{0} b \epsilon_{\text {fluoro } \mathrm{B}}\left(1-Y_{\mathrm{A}}\right) \text { [fluoro] }
\end{aligned}
$$

whenever expressed in terms of the total stoichiometric fluorophore concentration, [fluoro]. Here, $Y_{\mathrm{A}}$ and $1-Y_{\mathrm{A}}$ represent the mole number fraction of each type of solvated fluorophore, i.e., $Y_{\mathrm{A}}=$ [fluoro A] /[fluoro] and $1-Y_{\mathrm{A}}=$ [fluoro B] /[fluoro]. Inherent in the above treatment is the underlying assumption that neither solvent component forms a nonfluorescent association complex with the fluorophore. If such complexation does occur, then eq 6 describes only the fraction of the solute molecules that actually fluoresce.

Examination of eq 6 reveals that the observed PAH emission spectra for a binary solvent mixture are weighted mole fraction averages of the fluorophore's spectra in each of the two pure solvents, provided that the molar concentration of fluorophore remains constant for each series of measurements. Emission intensities are additive at each wavelength. In the case of a PAH solvent polarity probe such as pyrene, the calculated I/III emission intensity ratio (or $\mathrm{I} / \mathrm{II}$ in the case of BePy) is

$$
\begin{array}{r}
\mathrm{I} / \mathrm{III} \approx\left[Y_{\mathrm{A}} \mathrm{I}_{\text {solvent A }}+\left(1-Y_{\mathrm{A}}\right) \mathrm{I}_{\text {solvent } \mathrm{B}}\right] /\left[Y_{\mathrm{A}} \mathrm{III}_{\text {solvent A }}+\right. \\
\left.\left(1-Y_{\mathrm{A}}\right) \mathrm{III}_{\text {solvent B }}\right]
\end{array}
$$

also determined by the extent of preferential solvation. Here, we have assumed that both the I and III band emission wavelengths are solvent independent, which is not strictly true; hence, the approximately equal to sign is used. Rigorous applications require that intensity measurements be made at two fixed emission wavelengths.

Readers should note that the correct mathematical description for how emission intensity rations vary with solvent composition is not

$$
\mathrm{I} / \mathrm{III}=Y_{\mathrm{A}}(\mathrm{I} / \mathrm{III})_{\text {solvent A }}+\left(1-Y_{\mathrm{A}}\right)(\mathrm{I} / \mathrm{III})_{\text {solvent } \mathrm{B}}
$$

a simple weighted fraction average of ratios in the pure solvents except under the very special set of circumstances that III $_{\text {solvent A }}$ $=$ III $_{\text {solvent B. }}$ A number of researchers ${ }^{34-39}$ have invoked the questionable mathematical form of eq 8 in studies involving pyrene-tetraalkylammonium halide association and pyrenecyclodextrin inclusion complexes by assuming that the observed I/III ratio is a weighted average of the I/III ratio of the uncomplexed (free) pyrene and that of the complexed pyrene. More recently, Nakashima and co-workers ${ }^{40}$ employed eq 8 to investigate pyrene partitioning among polystyrene (PS) and poly(2-vinylpyridine) (PVP) microdomains in PS-PVP diblock copolymers.

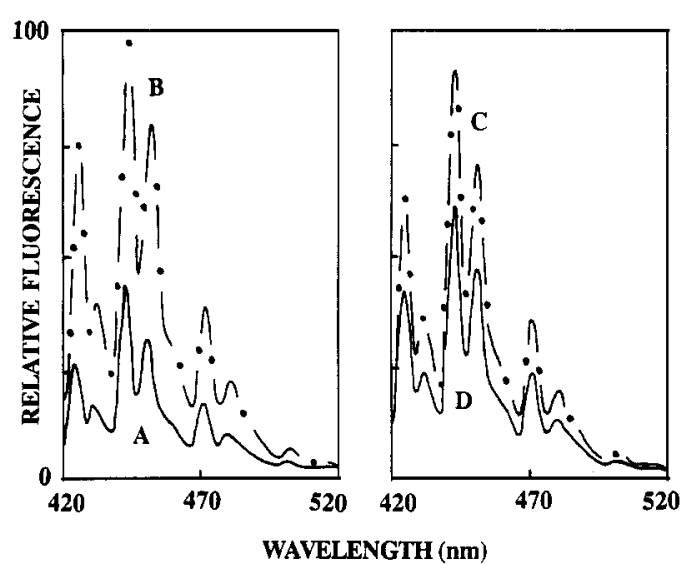

Figure 3. Fluorescence emission behavior of coronene dissolved in neat methanol ( $A$, solid line), in neat acetonitrile (B, dot-dashed line), and in a binary methanol-acetonitrile mixture ( $C$, dot-dashed line) having a stoichiometric volume fraction composition of $\phi_{\mathrm{MeOH}}=0.60$. Spectrum $D$ (solid line) represents the emission spectrum calculated using eqs 6 and 7, with a preferential solvation mole fraction of $Y_{\mathrm{MeOH}}=0.66$. After normalization to a common band intensity, spectra $C$ and $D$ are superimposable.

Application of eq 7 is relatively straightforward if the spectrofluorometer is equipped with data processing and manipulation software. The fluorescence emission spectra are recorded for the PAH probe dissolved in both pure solvents, and the measured I and III (I and II in the case of BePy) band intensities are substituted into the numerator and denominator, respectively. Values of $Y_{\mathrm{A}}$ and $1-Y_{\mathrm{A}}$ are computed from the measured I/III ratio for each binary solvent composition studied. These values are then used in eq 6 to generate the calculated fluorescence emission spectra, which are compared to the observed data. Careful attention is given to ensure that the entire detailed emission fine structure (wavelengths and all intensity ratios) is correctly produced, rather than just the experimental I/III ratio. Spectra A and B in Figure 3 represent the emission intensities of coronene dissolved in neat methanol and acetonitrile, respectively, scanned from 420 to $520 \mathrm{~nm}$. A value of $Y_{\mathrm{MeOH}}=0.66$ reproduced very accurately the observed coronene emission spectra at the binary solvent volume fraction composition of $\phi_{\mathrm{MeOH}}=$ 0.60 after normalization to a common band intensity (spectrum $C$ versus spectrum $D$ in Figure 3). Normalization corrects for small differences in experimental conditions, such as fluorophore concentration, ambient temperature, and excitation source intensity, which may occur during any given series of fluorescence measurements. In most cases there was less than a $1 \%$ difference between the emission intensities for the observed and calculated normalized spectra at each wavelength scanned.

Had one erroneously assumed that I/III intensity ratios were additive as implied in eq 8, then one would not necessarily generate the observed emission spectrum, much less the desired I/III intensity ratio. For example, in the case of coronene, the calculated I/III intensity ratios are Cor $=0.14$ and Cor $=0.62$ in pure $n$-heptane and 1,4-dioxane, respectively. The ratio is Cor $=0.37$ in the binary $n$-heptane $+1,4$-dioxane mixture at $\phi_{\text {Heptane }}=0.70$. Substituting these values into eq 8 , one computes a local mole fraction composition of $Y_{\text {heptane }}=0.52$. As shown in Figure 4, this particular value of $Y_{\text {heptane }}$ gives a I/III ratio of Cor $=0.49$ for the calculated spectrum generated via eq 6 . Moreover, the observed and calculated fluorescence spectra are not superimposable. Similar arguments illustrating the deficiencies in eq 8 can be made using benzo[e]pyrene as the spectroscopic probe molecule. Here, one can define three different solvent polarity scales based upon the I/II, I/III, and I/IV emission intensity ratios. ${ }^{16}$ Preferential solvation mole fractions computed from the $\mathrm{I} / \mathrm{II}$ ratio are significantly different from values based upon the I/III and I/IV ratios, despite the fact that the spectroscopic 


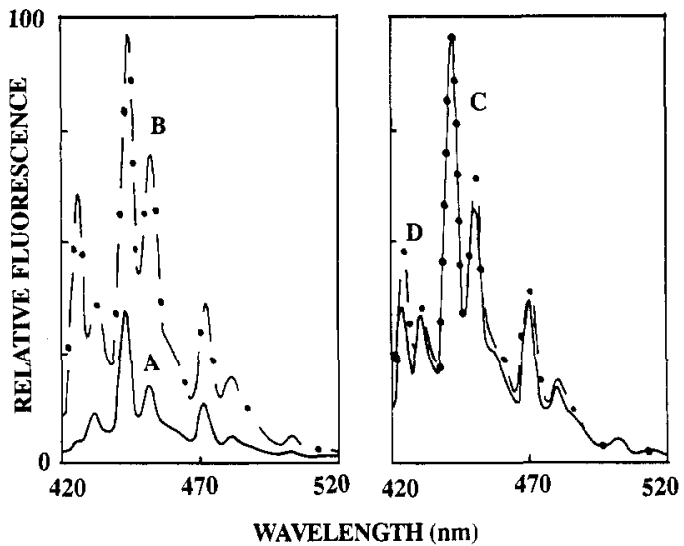

Figure 4. Fluorescence emission behavior of coronene dissolved in neat $n$-heptane (A, solid line), in neat 1,4-dioxane (B, dot-dashed line), and in a binary $n$-heptane $+1,4$-dioxane mixture ( $C$, solid line) having a stoichiometric volume fraction composition of $\phi_{n \text {-heptane }}=0.70$. Spectrum $D$ (dot-dashed line) represents calculated emission intensities from 420 to $520 \mathrm{~nm}$ assuming that I/III intensity ratios are additive; see eq 8 . Spectra $C$ and $D$ differ considerably in detailed emission fine structure.

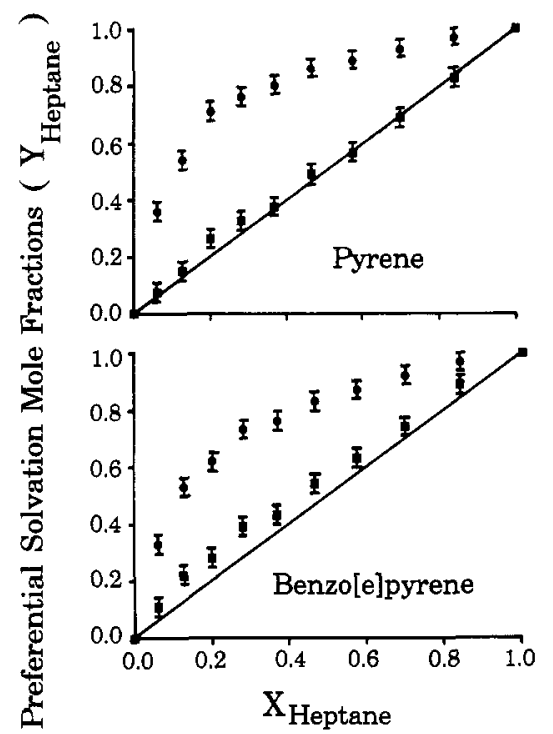

Figure 5. Preferential solvation of pyrene and benzo[e]pyrene dissolved in $n$-heptane +1,4-dioxane mixtures. Numerical values of $Y_{\text {beptane }}$ denoted as and were calculated from eqs 7 and 8 , respectively, using the observed I/III (or I/II in the case of BePy) emission intensity ratios. The $x$-axis denotes the stoichiometric mole fraction composition of the binary solvent.

probe sees only a single solvent microenvironment during the course of these measurements.

Figures 5-8 summarize the results of our preferential solvation computations for pyrene, benzo[e]pyrene, benzo[ghi]perylene, and coronene dissolved in binary $n$-heptane $+1,4$-dioxane and $n$-heptane + tetrahydrofuran mixtures. The nine stoichiometric binary compositions are represented as mole fractions. Uncertainties assigned to the various $Y_{\text {heptane }}$ and $\left(1-Y_{\text {heptane }}\right)$ values, indicated by the error bars, were based upon the reproducibility of the emission intensity ratios (circa \pm 0.02 ) and the range of possible values that predicted identical I/III ratios. For example, if numerical values of $\mathrm{I}_{\text {heptane }}=82.6, \mathrm{I}_{\mathrm{THF}}=549.6, \mathrm{III}_{\text {heptane }}=$ 606.9 , and $\mathrm{III}_{\mathrm{THF}}=910.0$ for coronene are substituted into eq 6 , then weighted fractions ranging from $Y_{\text {heptane }}=0.34$ to $Y_{\text {beptane }}$ $=0.36$ give the experimental intensity ratio of $\mathrm{I} / \mathrm{III}=0.48$ when rounded to the second decimal place. Local mole fraction compositions calculated from eq 8 (denoted by $\square$ ) are also included in Figures 5-8 to show that the two methods do return different numerical values of $Y_{\text {heptane. }}$

Examination of the various figures reveals that the computational method returned very smooth curves for how the degree

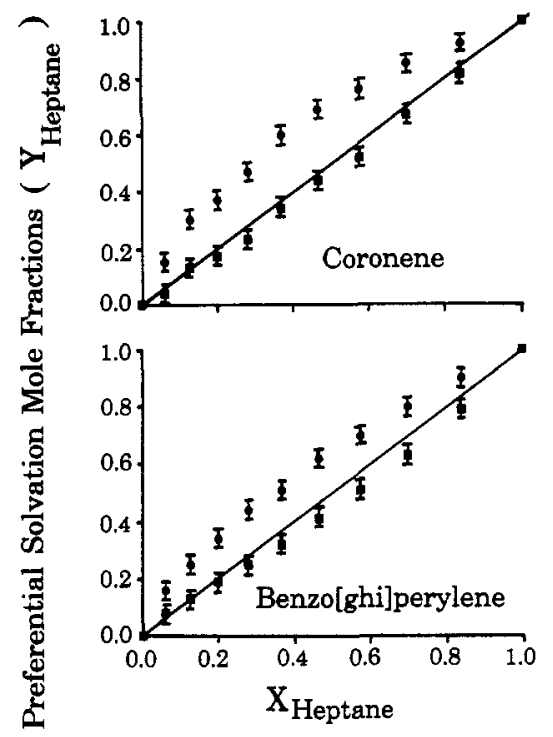

Figure 6. Preferential solvation of coronene and benzo[ghi]perylene dissolved in $n$-heptane +1 ,4-dioxane mixtures. Numerical values of

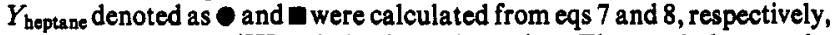
using the observed I/III emission intensity ratios. The $x$-axis denotes the stoichiometric mole fraction composition of the binary solvent.

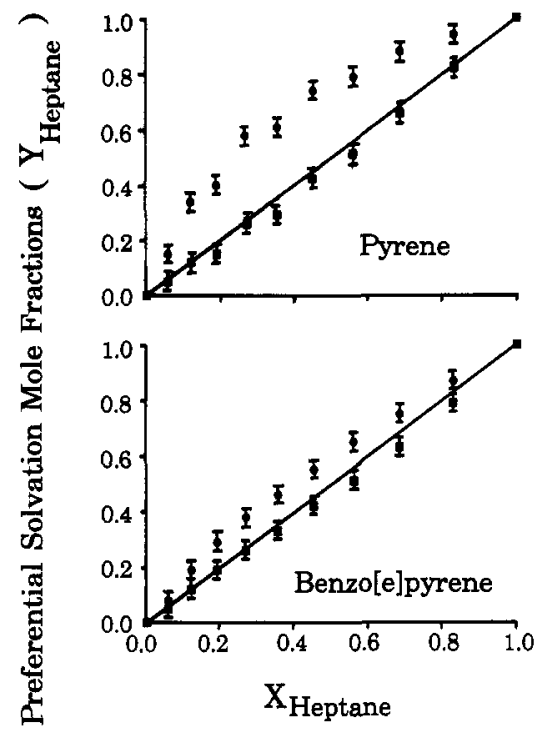

Figure 7. Preferential solvation of pyrene and benzo[e]pyrene dissolved in $n$-heptane + tetrahydrofuran mixtures. Numerical values of $Y_{\text {beptane }}$ denoted as - and $D$ were calculated from eqs 7 and 8 using the observed $\mathrm{I} / \mathrm{III}$ (or $\mathrm{I} / \mathrm{II}$ in the case of BePy) emission intensity ratios. The $x$-axis denotes the stoichiometric mole fraction composition of the binary solvent.

of presumed preferential solvation varies with solvent composition. In the ideal case, where the solvational sphere microenvironment is governed exclusively by the relative mole numbers of both solvent components, the local composition around the solute probe should equal the solution's stoichiometric mole fraction. For binary $n$-heptane $+1,4$-dioxane and $n$-heptane + tetrahydrofuran mixtures, there is an unexpectedly large local composition of the nonpolar $n$-heptane cosolvent around the polycyclic aromatic hydrocarbon probes. The degree of preferential solvation does decrease with increasing PAH molecular size. Naively, one would have expected that dipole-induced dipole interactions involving the oxygen lone electron pairs on the ether and the PAH's polarizable $\pi$-electron cloud would result in preferential solvation that would favor the more polar 1,4-dioxane or tetrahydrofuran cosolvent. Such interactions, however, may have led to the formation of nonfluorescent PAH-dioxane and/or PAH-tetrahydrofuran association complexes and would not have been properly accounted for in this particular preferential solvation 


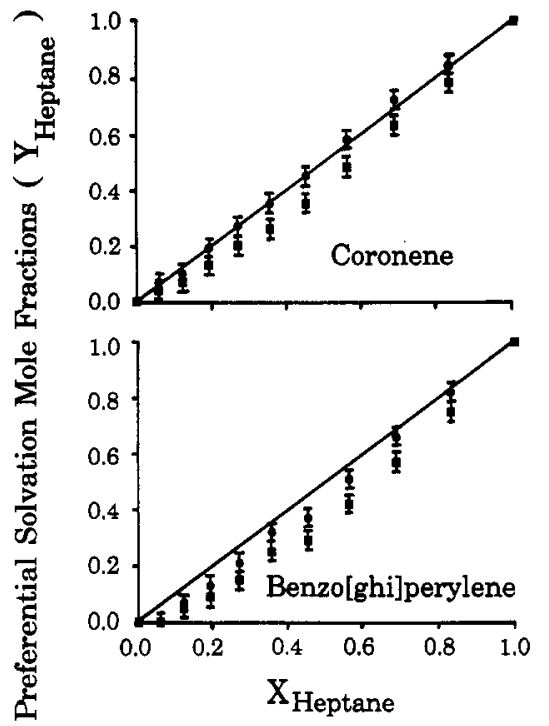

Figure 8. Preferential solvation of coronene and benzo[ghi]perylene dissolved in $n$-heptane + tetrahydrofuran mixtures. Numerical values of $Y_{\text {heprane }}$ denoted as 9 and 1 were calculated from eqs 7 and 8, respectively, using the observed I/III emission intensity ratios. The $x$-axis denotes the stoichiometric mole fraction composition of the binary solvent.

scheme. As noted previously, eq 7 assumes that each solvated fluorophore contributes to the observed fluorescence signal. Alternatively, the unexpected preferential solvation of $n$-heptane around the PAH fluorophore may be a calculational or chemical artifact of unknown origin. There is always the remote possibility that the large differences in emission intensities observed for several of the PAH solutes dissolved in pure $n$-heptane versus in pure dioxane (or in pure tetrahydrofuran) could have been caused by a trace impurity or fluorescence quenching agent in $n$-heptane. Mathematically, one must use a large fraction of the PAH spectrum in $n$-heptane to reproduce the intensity ratios observed in binary $n$-heptane + ether mixtures. Unfortunately, this happens to be one of the limitations of spectrofluorometric probe methods in general or many of the other experimental techniques that use $10^{-5} \mathrm{M}$ (or less) solute concentrations.

In closing, readers are reminded that it is fundamentally impossible to prove that a particular spectroscopic probe method is correct. One can demonstrate, however, that a given method is consistent with a wide range of experimental observations, which implies that the method and assumptions made therein may be correct. Similarly, it can be shown that a given spectroscopic probe method is inconsistent with experimental data so that the method must be either incorrect or incomplete. It is hoped that the ideas presented in this paper will prompt a critical reexamination of the relative merits of the various spectrofluorometric probe methods, eq 7 versus eq 8 , in hopes of achieving a better understanding of solute-solvent interactions in fluid solution.

Acknowledgment. This work is supported in part by grants from the National Science Foundation (Grant No. CTS-8922485), by the University of North Texas Research Council, and by a National Science Foundation Doctoral Research Fellowship awarded to S.A.T.
The Journal of Physical Chemistry, Vol. 97, No. 43, 199311203

\section{References and Notes}

(1) Dimroth, K.; Reichardt, C.; Siepmann, T.; Bohlmann, F. Liebigs Ann. Chem. 1963, 661, 1.

(2) Reichardt, C. Solvents and Solvent Effects in Organic Chemistry, 2nd ed.; VCH Publishers: New York, 1988.

(3) Chatterjee, P.; Laha, A. K.; Bagchi, S. J. Chem. Sac., Faraday Trans. $1992,88,1675$.

(4) Chatterjee, P.; Bagchi, S. J. Phys. Chem. 1991, 95, 3311. 1785 .

(5) Chatterjee, P.; Bagchi, S. J. Chem. Soc., Faraday Trans. 1990, 86 ,

(6) Dong, D. C.; Winnik, M. A. Can. J. Chem. 1984, 62, 2560. 2039.

(7) Kalyanasundaram, K.; Thomas, J. K. J. Am. Chem. Soc. 1977, 99,

(8) Szpakowska, M.; Nagy, O. B. J. Chem. Soc., Faraday Trans. 11989, $85,2891$.

(9) Zurawsky, W. P.; Scarlata, S. F. J. Phys. Chem. 1992, 96, 6012.

(10) Bosch, E.; Roses, M. J. Chem. Sac., Faraday Trans. 1992, 88, 3541.

(11) Chatterjee, P.; Bagchi, S. J. Chem. Soc., Faraday Trans. 1991, 87, 587.

(12) Tamori, K.; Watanabe, Y.; Esumi, K. Langmuir 1992, 8, 2344.

(13) Sun, Y. P.; Bennett, G.; Johnston, K. P.; Fox, M. A. J. Phys. Chem. $1992,96,10001$.

(14) Waris, R.; Rembert, M. A.; Sellers, D. M.; Acree, W. E., Jr.; Street, K. W., Jr.; Poole, C. F.; Shetty, P. H.; Fetzer, J. C. Appl. Spectrosc. 1988, 42, 1525 .

(15) Waris, R.; Rembert, M. A.; Sellers, D. M.; Acree, W. E., Jr.; Street,

K. W. Jr.; Fetzer, J. C. Analyst 1989, 114, 195.

(16) Waris, R.; Street, K. W., Jr.; Acree, W. E., Jr.; Fetzer, J. C. Appl. Spectrosc. 1989, 43, 845 .

(17) Acree, W. E., Jr.; Tucker, S. A.; Zvaigzne, A. I.; Street, K. W., Jr.; Fetzer, J. C.; Grutzmacher, H.-F. Appl. Spectrosc. 1990, 44, 477.

(18) Acree, W. E., Jr.; Tucker, S. A.; Cretella, L. E.; Zvaigzne, A. I.; Street, K. W., Jr.; Fetzer, J. C.; Nakasuji, K.; Murata, I. Appl. Spectrosc. $1990,44,951$.

(19) Acree, W. E., Jr.; Zvaigzne, A. I.; Fetzer, J. C. Appl. Spectrosc. $1990,44,1193$.

(20) Tucker, S. A.; Acree, W. E., Jr.; Tanga, M. J. Appl. Spectrosc. 1991, 45,57 .

(21) Tucker, S. A.; Teng, I.-L.; Acree, W. E., Jr.; Fetzer, J. C. Appl. Spectrosc. 1991, 45, 186.

(22) Tucker, S. A.; Zvaigzne, A. I.; Acree, W.E., Jr.; Fetzer, J. C.; Zander, M. Appl. Spectrosc. 1991, 45, 424.

(23) Tucker, S. A.; Acree, W. E., Jr.; Tanga, M. J. Appl. Spectrosc. 1991, 45,911 .

(24) Acree, W. E., Jr.; Tucker, S. A.; Fetzer, J. C. Polycyclic Aromat. Compds. 1991, 2, 75.

(25) Tucker, S. A.; Acree, W. E., Jr.; Cho, B. P.; Harvey, R. C.; Fetzer, J. C. Appl. Spectrosc. 1991, 45, 1991.

(26) Tucker, S. A.; Acree, W. E., Jr.; Tanga, M. J.; Tokita, S.; Hiruta, K.; Langhals, H. Appl. Spectrosc. 1992, 46, 229.

(27) Amszi, V. L.; Cordero, Y.; Smith, B.; Tucker, S. A.; Acree, W. E., Jr.; Yang, C.; Abu-Shaqara, E.; Harvey, R. G. Appl. Spectrosc. 1992, 46, 1156.

(28) Tucker, S. A.; Bates, H. C.; Amszi, V. L.; Acree, W. E., Jr.; Lee, H.; Raddo, P. D.; Harvey, R. G.; Fetzer, J. C.; Dyker, G. Anal. Chim. Acta 1993, $278,269$.

(29) Street, K. W., Jr.; Acree, W. E., Jr. J. Liq. Chromatogr. 1986, 9, 2799.

(30) Procyk, A. D.; Bissell, M.; Street, K. W., Jr.; Acree, W. E., Jr. J. Pharm. Sci. 1987, 76, 621.

(31) Carr, J. W.; Harris, J. M. Anal. Chem. 1986, 58, 626.

(32) Stahlberg, J.; Almgren, M. Anal. Chem. 1985, 57, 817.

(33) Street, K. W., Jr,; Acree, W. E., Jr. Analyst 1986, 111, 1197.

(34) Almgren, M.; Grieser, F.; Thomas, J. K. J. Am. Chem. Soc. 1979. $101,279$.

(35) Kusumoto, Y. Chem. Phys. Lett. 1987, 136, 535.

(36) Zung, J. B.; Muñoz de la Peña, A.; Ndou, T. T.; Warner, I. M. J. Phys. Chem. 1991, 95, 6701.

(37) Mufioz de la Peña, A.; Ndou, T.; Zung, J. B.; Warner, I. M. J. Phys. Chem. 1991, 95, 3330.

(38) Muñoz de la Peña, A.; Ndou, T.; Zung, J. B.; Green, K. L.; Live, D. H.; Warner, I. M. J. Am. Chem. Soc. 1991, I13, 1572

(39) Muñoz de la Peña, A.; Ndou, T. T.; Anigbogu, V. C.; Warner, I. M. Anal. Chem. 1991, 63, 1018.

(40) Nakashima, K.;Winnik, M. A.; Dai, K.H.;Kramer, E. J.; Washiyama, J. Macromolecules 1992, 25, 6866 . 